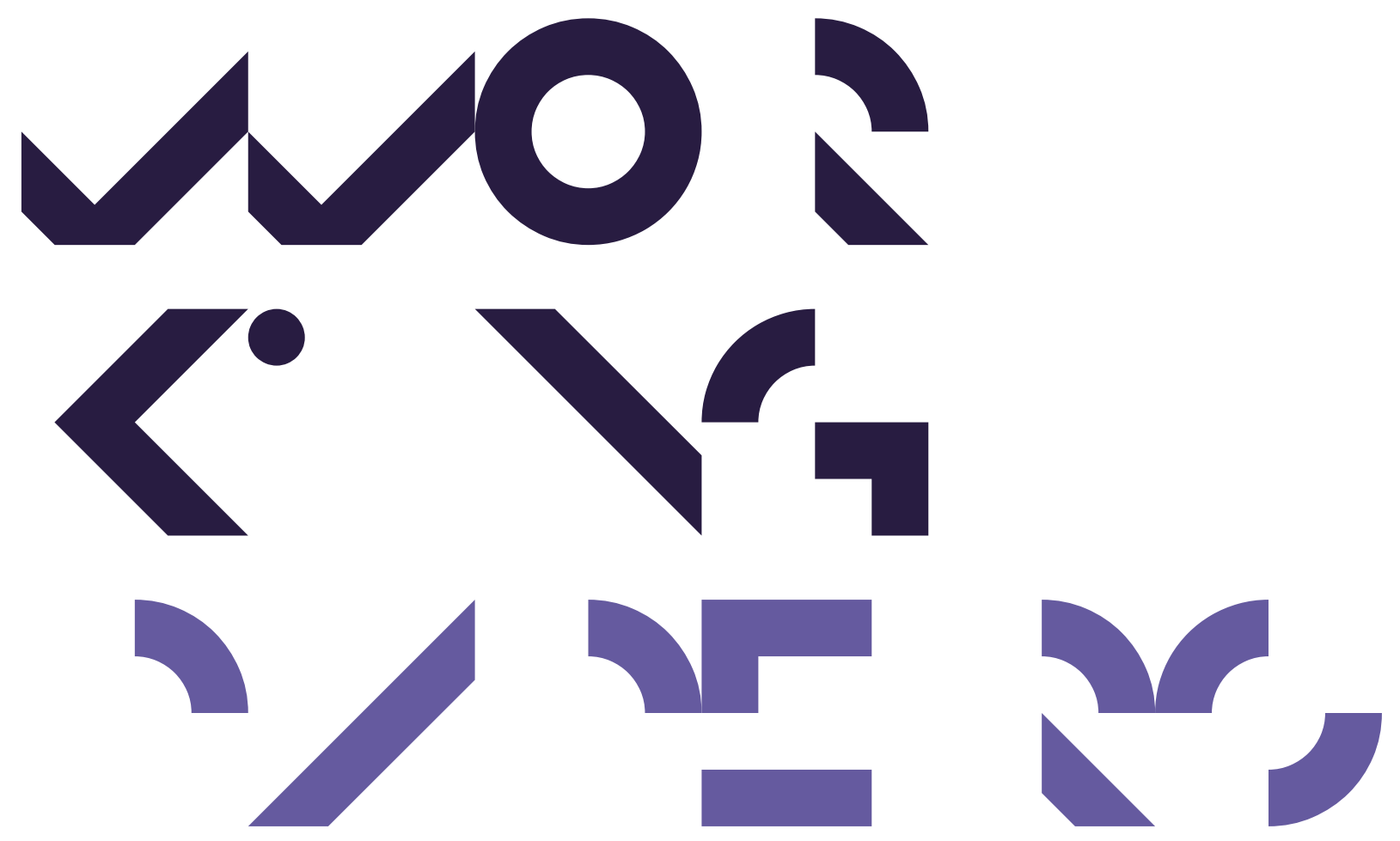

Economics Working Papers

2015-15

A Note on Quality Disclosure and Competition Jos Jansen

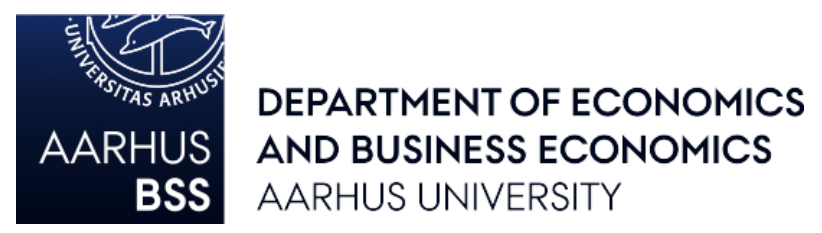




\title{
A Note on Quality Disclosure and Competition
}

\author{
Jos Jansen \\ Aarhus University* \\ Max Planck Institute for Research on Collective Goods
}

July 2015

\begin{abstract}
Competitive pressure is lower in markets where goods are more differentiated. I analyze how a change in the degree of horizontal product differentiation affects the incentives of duopolists to disclose quality information. If disclosure is costly, then a firm discloses high qualities but conceals low qualities in equilibrium. The higher the disclosure cost, the higher the equilibrium threshold below which firms conceal quality information. I show that the effect of product differentiation on quality disclosure depends on the cost of disclosure. For low (high) disclosure costs, a firm discloses more (less) quality information if goods become more differentiated.
\end{abstract}

Keywords: Hotelling model, quality, transportation cost, product differentiation, information disclosure, disclosure cost, competitive pressure

JEL Codes: D82, D83, L13, L15, M31

*Address: Dept. of Economics and Business Economics, Aarhus University, Fuglesangs Allé 4 (Building 2632/L), DK-8210 Aarhus V, Denmark; E-mail: <jjansen@econ.au.dk> 


\section{Introduction}

The relationship between market structure and incentives to voluntarily disclose quality information has recently received some attention in the economic literature (e.g., see Dranove and Jin, 2010, for a review). It is an important issue, as it is relevant for understanding how disclosure regulation may affect behavior in different markets.

Levin et al. (2009) make an interesting contribution to this literature by comparing quality-disclosure strategies in a monopoly with duopoly strategies. A multiproduct monopoly coordinates its pricing and disclosure choices, whereas singleproduct duopolists make their disclosure and pricing choices non-cooperatively. Interestingly, Levin et al. show that a monopolistic firm has a greater incentive to disclose quality information than a duopolistic firm. That is, in their setting, more intense competition gives a lower expected amount of quality disclosure.

Increasing the number of firms in an industry (i.e., replacing cooperative choices by non-cooperative choices) is one way of intensifying competition. An alternative way to increase the competitive pressure among firms is to increase the degree of product substitutability. Competition tends to be fiercer among firms that produce closer substitutes (Boone, 2000). In a straightforward extension of the duopoly model in Levin et al. (2009), I show that an increase of the degree of product substitutability has an ambiguous effect on a duopolist's quality-disclosure strategy. In particular, the effect of product substitutability on disclosure strategies depends on the cost of disclosure. For low disclosure costs, firms disclose fewer quality levels if their goods become closer substitutes. The reverse holds for high disclosure costs, i.e., there firms with closer substitutes disclose more quality information. In other words, the effects of competition on quality disclosure depend on the way in which one models competition.

In the next section, I describe the model. Section 3 briefly analyzes the equilibrium strategies, and characterizes the effects of changing the degree of product substitutability. Finally, section 4 concludes the paper.

\section{The Model}

I extend the duopoly model of Levin et al. (2009) by allowing the consumers' transportation costs to differ from 1 . That is, two risk-neutral firms supply differentiated goods at zero cost from the two extremes of the unit interval (Hotelling duopoly). Firm 0 supplies good 0 from the origin $(x=0)$, and firm 1 supplies good 1 from $x=1$. Good $i$ has quality $q_{i}$ for $i=0,1$. The qualities are exogenously determined 
by independent draws from the uniform distribution over $[0,1]$.

There is a mass 1 of risk-neutral consumers who are uniformly distributed along the unit interval $[0,1]$. Each consumer demands at most one unit of the good. Consumer $x \in[0,1]$ gets utility $\psi+q_{0}-\tau x-p_{0}$ if she buys good 0 at price $p_{0}$, whereas she gets utility $\psi+q_{1}-\tau(1-x)-p_{1}$ from buying good 1 at price $p_{1}$. The common value component $\psi>0$ is sufficiently high to give full market coverage. The consumers' transportation cost per unit of distance from a good, $\tau>0$, captures the degree of product differentiation. A reduction of $\tau$ makes goods closer substitutes, and this intensifies price competition between firms 0 and 1 (Boone, 2000). In this note, I analyze the effects of varying $\tau$ whereas Levin et al. (2009) restrict attention to $\tau=1$. Nevertheless, I assume that $\tau$ becomes neither too low nor too high, i.e., $\frac{1}{3}<\tau<\psi$, in order to focus on interior equilibrium choices. ${ }^{1}$

Also the game's timing follows Levin et al. (2009). First, firm $i$ privately learns the quality of its good, $q_{i}$, for $i=0,1$. Firms simultaneously choose their disclosure strategies, i.e., $D_{i}:[0,1] \rightarrow\{0,1\}$ for $i=0,1$. If firm $i$ discloses its quality, i.e., $D_{i}\left(q_{i}\right)=1$, then it incurs the cost $\delta>0$. The choice $D_{i}\left(q_{i}\right)=0$ denotes concealment of quality $q_{i}$ by firm $i$. Second, the firms simultaneously choose their prices, i.e., $p_{i} \geq 0$ for $i=0,1$. Finally, the consumers observe the disclosure and pricing choices of the firms, and each consumer chooses which good she buys.

Given disclosure choice $d_{i} \in\{0,1\}$, the consumers perceive the quality of good $i$ as follows:

$$
\widetilde{q}_{i}\left(d_{i}\right) \equiv d_{i} q_{i}+\left(1-d_{i}\right) E\left\{q_{i} \mid D_{i}=0\right\}
$$

The marginal consumer, who is indifferent between buying good 0 and good 1 , determines the demanded quantities for the firms. In particular, for $d_{i}, d_{j} \in\{0,1\}$ and $i, j=0,1$ with $i \neq j$, the demand for $\operatorname{good} i$ is:

$$
x_{i}^{d}\left(p_{i}, p_{j} ; d_{i}, d_{j}\right)=\frac{1}{2 \tau}\left(\tau+\widetilde{q}_{i}\left(d_{i}\right)-\widetilde{q}_{j}\left(d_{j}\right)+p_{j}-p_{i}\right) .
$$

The profit of firm $i$ therefore equals:

$$
\pi_{i}\left(p_{i}, p_{j} ; d_{i}, d_{j}\right)=p_{i} x_{i}^{d}\left(p_{i}, p_{j} ; d_{i}, d_{j}\right)-\delta d_{i}
$$

I restrict the analysis to symmetric perfect Bayesian equilibria (PBE).

\footnotetext{
${ }^{1}$ If $\tau \leq 1 / 3$, then there may be instances in which a supplier of a low-quality good is driven out of the market by a supplier of a high-quality good By contrast, if $\tau \geq \psi$, then there may be instances in which firms are local monopolies.
} 


\section{$3 \quad$ Equilibrium Strategies}

First, I describe the equilibrium prices. As Levin et al. (2009) argue, there is no signaling role for prices in this model. Given the perceived qualities, firm $i$ 's equilibrium price is (for disclosure choices $d_{i}, d_{j} \in\{0,1\}$ and $i, j=0,1$ with $i \neq j$ ):

$$
p_{i}^{*}\left(d_{i}, d_{j}\right)=\tau+\frac{1}{3}\left[\widetilde{q}_{i}\left(d_{i}\right)-\widetilde{q}_{j}\left(d_{j}\right)\right] .
$$

Firm $i$ 's profit given equilibrium prices equals:

$$
\begin{aligned}
\pi_{i}^{*}\left(d_{i}, d_{j}\right) & =\frac{1}{2 \tau} p_{i}^{*}\left(d_{i}, d_{j}\right)^{2}-\delta d_{i} \\
& =\frac{1}{18 \tau}\left(3 \tau+\widetilde{q}_{i}\left(d_{i}\right)-\widetilde{q}_{j}\left(d_{j}\right)\right)^{2}-\delta d_{i} .
\end{aligned}
$$

Second, I analyze the information-disclosure strategies in equilibrium. A firm's disclosure strategy is a step function which has quality threshold $q^{*}(\delta, \tau)$ such that the firm discloses only quality draws above $q^{*}(\delta, \tau)$. That is, the perceived quality consistent with this strategy is: $\widetilde{q}_{i}\left(D_{i}\right)=D_{i} q_{i}+\left(1-D_{i}\right) q^{*}(\delta, \tau) / 2$, because $E\left\{q_{i} \mid q_{i} \leq q^{*}(\delta, \tau)\right\}=\frac{1}{2} q^{*}(\delta, \tau)$. The following proposition characterizes the disclosure strategy in more detail.

Proposition 1 There exists a threshold quality $q^{*}(\delta, \tau)$ with $0<q^{*}(\delta, \tau) \leq 1$ such that in the unique symmetric PBE firms disclose qualities greater than $q^{*}(\delta, \tau)$, whereas they conceal qualities smaller than or equal to $q^{*}(\delta, \tau)$. In particular, there exists a threshold disclosure cost, $\delta^{*}(\tau) \equiv \frac{12 \tau+1}{72 \tau}$, such that: (i) $0<q^{*}(\delta, \tau)<1$ and $q^{*}(\delta, \tau)$ is increasing in $\delta$ for $0<\delta<\delta^{*}(\tau)$; and (ii) $q^{*}(\delta, \tau)=1$ for $\delta \geq \delta^{*}(\tau)$.

Proof. Assume that firm $i$ anticipates that its competitor discloses all quality levels above the threshold quality $q^{*}>0$ and conceals all other qualities. Further, assume that consumers perceive firm $i$ 's quality to be $\widetilde{q}_{i}\left(d_{i}\right)=d_{i} q_{i}+\left(1-d_{i}\right) q^{*} / 2$ for $d_{i} \in\{0,1\}$. Then quality disclosure yields the expected profit:

$$
q^{*} \frac{1}{18 \tau}\left(3 \tau+q_{i}-\frac{1}{2} q^{*}\right)^{2}+\int_{q^{*}}^{1} \frac{1}{18 \tau}\left(3 \tau+q_{i}-x\right)^{2} d x-\delta .
$$

By contrast, quality concealment by firm $i$ yields the expected profit:

$$
q^{*} \frac{\tau}{2}+\int_{q^{*}}^{1} \frac{1}{18 \tau}\left(3 \tau+\frac{1}{2} q^{*}-x\right)^{2} d x
$$


The difference between (6) and (7) equals:

$$
\begin{aligned}
\Delta\left(q_{i}, q^{*}, \delta, \tau\right) \equiv & q^{*} \frac{1}{18 \tau}\left[\left(3 \tau+q_{i}-\frac{1}{2} q^{*}\right)^{2}-9 \tau^{2}\right] \\
& +\int_{q^{*}}^{1} \frac{1}{18 \tau}\left[\left(3 \tau+q_{i}-x\right)^{2}-\left(3 \tau+\frac{1}{2} q^{*}-x\right)^{2}\right] d x-\delta .
\end{aligned}
$$

$\Delta$ is negative for $q_{i}=0$, and it is increasing in firm $i$ 's quality $q_{i}$. Hence, firm $i$ 's profit-maximizing disclosure strategy is a step function with threshold quality $0<q^{*}(\delta, \tau) \leq 1$ such that the firm conceals quality information only if $q_{i} \leq q^{*}(\delta, \tau)$.

For $q_{i}=q^{*}$, equation (8) simplifies as follows:

$$
\Delta^{*}\left(q^{*}, \delta, \tau\right)=q^{*} \frac{1}{18 \tau}\left[3 \tau+\frac{1}{2}\left(\frac{3}{2} q^{*}-1\right)\right]-\delta .
$$

It follows from $(9)$ that $\Delta^{*}(0, \delta, \tau)<0$. Further, $\Delta^{*}(1, \delta, \tau)>0$ if and only if $\delta<$ $\delta^{*}(\tau)$, where $\delta^{*}(\tau)=\frac{12 \tau+1}{72 \tau}$. Differentiating $\Delta^{*}$ with respect $q^{*}$ to gives:

$$
\frac{\partial \Delta^{*}\left(q^{*}, \delta, \tau\right)}{\partial q^{*}}=\frac{1}{18 \tau}\left(3 \tau+\frac{1}{2}\left[3 q^{*}-1\right]\right) .
$$

Since $\tau>\frac{1}{3}$ by assumption, $\Delta^{*}$ is increasing in $q^{*}$. Consequently, if $\delta<\delta^{*}(\tau)$, then there exists a unique interior quality threshold $q^{*}(\delta, \tau)$ with $0<q^{*}(\delta, \tau)<1$ such that $\Delta^{*}\left(q^{*}(\delta, \tau), \delta, \tau\right)=0$. Further, if $\delta \geq \delta^{*}(\tau)$, then $\Delta^{*}\left(q^{*}, \delta, \tau\right) \leq 0$ for all $q^{*}$, and therefore the quality threshold $q^{*}(\delta, \tau)$ equals 1 .

This result is a straightforward extension of Proposition 1 in Levin et al. (2009) by allowing for $\tau \neq 1$. It is intuitive (and immediate to show) that the equilibrium threshold quality is increasing in disclosure $\operatorname{cost} \delta$, i.e., $\partial q^{*}(\delta, \tau) / \partial \delta \geq 0$ for all $\delta .{ }^{2}$ The higher the cost of disclosure, the fewer qualities does a firm disclose in equilibrium.

Further, the proof of Proposition 1 has the following immediate implication.

Corollary 1 The threshold disclosure cost, $\delta^{*}(\tau)=\frac{12 \tau+1}{72 \tau}$, beyond which a firm does not disclose any information, is decreasing in transportation cost $\tau$.

This means that more intense competition yields more quality disclosure if disclosure is sufficiently costly. For any transportation cost parameter $\tau^{\prime}$ and disclosure cost $\delta^{\prime}=\delta^{*}\left(\tau^{\prime}\right)$, a firm does not disclose any information in equilibrium. A reduction of $\tau$

\footnotetext{
${ }^{2}$ This follows from the observations that $\Delta\left(q^{*}, \delta, \tau\right)$ in $(8)$ is decreasing in $\delta$, and $q^{*}(\delta, \tau)$ is the root of $\Delta\left(q^{*}, \delta, \tau\right)=0$, where $\Delta\left(q^{*}, \delta, \tau\right)$ is increasing in $q^{*}$.
} 
to $\tau^{\prime \prime}<\tau^{\prime}$ intensifies competition between the firms, and it increases the critical disclosure cost, i.e., $\delta^{*}\left(\tau^{\prime \prime}\right)>\delta^{*}\left(\tau^{\prime}\right)$. Hence, for disclosure cost $\delta^{\prime}$, the more competitive firms disclose qualities between $q^{*}\left(\delta^{\prime}, \tau^{\prime \prime}\right)$ and 1 , as Proposition 1(i) applies. ${ }^{3}$ In other words, fiercer competition yields more disclosure of quality for a sufficiently high cost of disclosure. This observation differs from the finding in Levin et al. (2009), who intensify competition by switching from coordination to competition.

The following result characterizes how equilibrium disclosure strategy of Proposition 1 depends on parameter $\tau$ for any cost of disclosure.

Proposition 2 The equilibrium threshold quality $q^{*}(\delta, \tau)$ from Proposition 1 is:

(a) decreasing in $\tau$ if $0<\delta<\frac{1}{9}$, (b) constant in $\tau$ if $\delta=\frac{1}{9}$, and (c) increasing in $\tau$ for $\frac{1}{9}<\delta<\delta^{*}(\tau)$, where $\delta^{*}(\tau)$ is defined in Proposition 1.

Proof. Solving $\Delta^{*}\left(q^{*}, \delta, \tau\right)=0$ for $q^{*}$, with $\Delta^{*}$ as in (9), gives:

$$
q^{*}(\delta, \tau)=\frac{1}{3}\left(\sqrt{(6 \tau-1)^{2}+216 \tau \delta}-(6 \tau-1)\right) .
$$

Partial differentiation of $q^{*}(\delta, \tau)$ with respect to $\tau$ gives:

$$
\frac{\partial q^{*}(\delta, \tau)}{\partial \tau}=2\left(\frac{(6 \tau-1)+18 \delta}{\sqrt{(6 \tau-1)^{2}+216 \tau \delta}}-1\right) .
$$

(i) It is easily verified that $\partial q^{*}(0, \tau) / \partial \tau=\partial q^{*}\left(\frac{1}{9}, \tau\right) / \partial \tau=0$.

(ii) The partial cross-derivative of $q^{*}(\delta, \tau)$ equals:

$$
\frac{\partial^{2} q^{*}(\delta, \tau)}{\partial \tau \partial \delta}=\frac{36[108 \tau \delta-(6 \tau-1)]}{\left[(6 \tau-1)^{2}+216 \tau \delta\right]^{3 / 2}} .
$$

Consequently, the critical disclosure cost $\delta^{o}(\tau)=(6 \tau-1) /(108 \tau)$ exists, with $0<$ $\delta^{o}(\tau)<\frac{1}{9}$, such that $\partial^{2} q^{*}(\delta, \tau) /(\partial \tau \partial \delta) \lessgtr 0$ if and only if $\delta \lessgtr \delta^{o}(\tau)$.

It follows from (i)-(ii) that: $\partial q^{*}(\delta, \tau) / \partial \tau<0$ for $0<\delta<\frac{1}{9}$, whereas $\partial q^{*}(\delta, \tau) / \partial \tau>0$ for $\delta>\frac{1}{9}$.

This result has the following intuition. The trade-off between a firm's additional expected product-market profit from disclosure (i.e., the first two terms of $\Delta$ in (8)) and the cost of disclosure (i.e., $\delta$ ) determines the firm's incentive to disclose quality information. The disclosure cost does not depend on $\tau$, whereas the additional product-market profit from disclosure does. If a firm has a quality above the conditionally expected quality (i.e., $q_{i}>\frac{1}{2} q^{*}$ ), then the degree of product differentiation has

\footnotetext{
${ }^{3}$ That is, $\delta^{\prime}<\delta^{*}\left(\tau^{\prime \prime}\right)$ and $q^{*}\left(\delta^{\prime}, \tau^{\prime \prime}\right)<1$, since $q^{*}\left(\delta, \tau^{\prime \prime}\right)$ is increasing in $\delta$ with $q^{*}\left(\delta^{*}\left(\tau^{\prime \prime}\right), \tau^{\prime \prime}\right)=1$.
} 
two conflicting effects on the firm's additional product-market profit from disclosure. ${ }^{4}$ On the one hand, the additional profit is decreasing in $\tau$, if the firm's competitor conceals its quality (i.e., the first term of $\Delta$ in (8) decreases in $\tau$ ). This happens with probability $q^{*}$. On the other hand, the firm's additional product-market profit from disclosure is increasing in $\tau$ if the competitor discloses information (i.e., the second term of $\Delta$ in (8) increases in $\tau$ ). This happens if $q_{j}>q^{*}$ which has probability $1-q^{*}$. The former, negative effect dominates if and only if the firm's quality is high, i.e., $q_{i}>1-\frac{1}{2} q^{*}$. Conversely, the latter, positive effect dominates for intermediate quality levels (i.e., for $\frac{1}{2} q^{*}<q_{i}<1-\frac{1}{2} q^{*}$ ).

The effect which plays a role for the firm's disclosure strategy is the effect which dominates at the margin, i.e., for $q_{i}=q^{*}$. If $q^{*}<\frac{2}{3}$ (which happens for $\delta<\frac{1}{9}$ ), then $q^{*}<1-\frac{1}{2} q^{*}$, and therefore the firm's additional product-market profit from disclosure is increasing in $\tau$ for $q_{i}=q^{*}$. This enhanced benefit from disclosure yields more disclosure in equilibrium (i.e., the disclosure threshold $q^{*}(\delta, \tau)$ decreases in $\tau$, as Proposition 2(a) shows). Conversely, if $q^{*}>\frac{2}{3}$ (i.e., if $\delta>\frac{1}{9}$ ), then an increase of $\tau$ makes disclosure less profitable at the margin (since $q^{*}>1-\frac{1}{2} q^{*}$ ), and the firm discloses fewer quality levels in equilibrium (Proposition 2(c)).

Figure 1 illustrates the effects of changing $\tau$ from $\frac{1}{2}$ to 1 on the quality disclosure threshold $q^{*}(\delta, \tau)$. The bold curve sketches $q^{*}\left(\delta, \frac{1}{2}\right)$ for different costs of disclosure whereas the thin curve sketches $q^{*}(\delta, 1)$. The two curves cross twice. First, without a cost of disclosure (i.e., $\delta=0$ ) the firms disclose all quality information, i.e., $q^{*}(0, \tau)=0$ for all $\tau$. This is an unraveling result (Milgrom, 2008, and Dranove and Jin, 2010). Second, the curves cross for disclosure $\operatorname{cost} \delta=\frac{1}{9}$, as Proposition 2(b) predicts, since $q^{*}\left(\frac{1}{9}, \tau\right)=\frac{2}{3}$ for all $\tau$. For $\delta<\frac{1}{9}$, Figure 1 illustrates that the threshold $q^{*}$ decreases in the degree of product differentiation (Proposition 2(a)), since the curve of $q^{*}(\delta, 1)$ lies below the curve of $q^{*}\left(\delta, \frac{1}{2}\right)$, whereas the reverse holds for $\delta>\frac{1}{9}$ (Proposition 2(c)).

In other words, the effect of a change in the degree of product differentiation, $\tau$, on quality disclosure depends on the cost of disclosure. On the one hand, if disclosure is not very costly (i.e., $0<\delta<\frac{1}{9}$ ), then firms are more likely to disclose quality information if their goods become more differentiated. That is, firms disclose less in more competitive markets, which is in line with the qualitative result in Proposition 3 of Levin et al. (2009). On the other hand, if disclosure is sufficiently costly, then

\footnotetext{
${ }^{4}$ If a firm's quality is below the conditionally expected quality (i.e., $q_{i} \leq \frac{1}{2} q^{*}$ ), then the firm has no incentive to disclose its quality, since disclosure reduces the firm's product-market profit, and it has a direct disclosure cost. In this case, the additional profit from disclosure is decreasing in $\tau$. However, this effect does not play a role at the margin for a firm's disclosure strategy.
} 


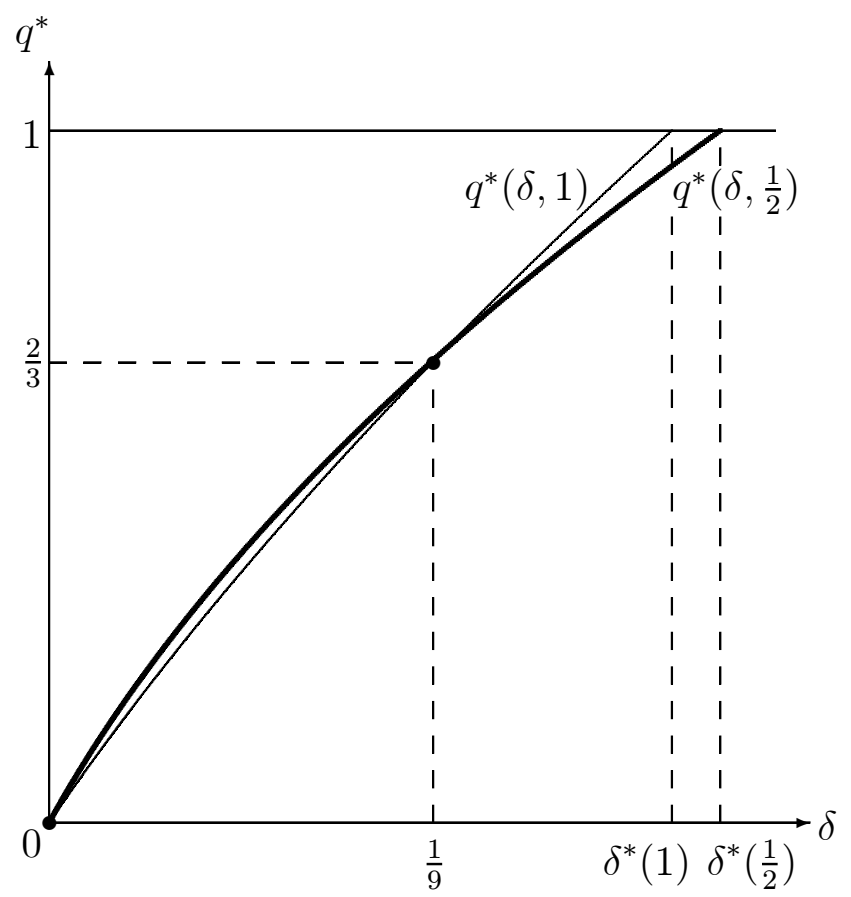

Figure 1: Threshold $q^{*}(\delta, \tau)$ plotted against disclosure cost $\delta$ for $\tau=\frac{1}{2}$ and $\tau=1$.

the reverse holds. With high disclosure costs, the suppliers of more differentiated goods are less likely to disclose quality information. That is, competitive pressure has a positive effect on the expected amount of quality disclosure in this case. This contrasts with the qualitative result in Proposition 3 of Levin et al. (2009).

\section{Conclusion}

This note attempts to contribute to the current debate on the effects of competition intensity on the disclosure of quality information. The paper considers an alternative way of modeling competitive pressure. Instead of increasing the number of independent firms in the market (Levin et al., 2009), I increase the degree of product substitutability. An increase of the degree of product substitutability has a different effect on a firm's disclosure incentives than a change in the number of firms. Whether a higher degree of product substitutability yields more or less quality disclosure depends on the cost of disclosure. By contrast, intensifying competition by switching from monopolistic to duopolistic supply yields less quality disclosure for any cost of disclosure (Levin et al., 2009). In short, the effect of competition on the incentive to disclose quality information depends on the particular way in which one models competitive pressure. 


\section{References}

Boone, J. (2000) "Competitive Pressure: the Effects on Investments in Product and Process Innovation," RAND Journal of Economics 31 (3), 549-569

Dranove, D., And G.Z. Jin (2010) "Quality Disclosure and Certification: Theory and Practice," Journal of Economic Literature 48 (4), 935-963

Levin, D., Peck, J. And L. Ye (2009) "Quality Disclosure and Competition," Journal of Industrial Economics 47 (1), 167-196

Milgrom, P. (2008) "What the Seller Won't Tell You: Persuasion and Disclosure in Markets," Journal of Economic Perspectives 22 (2), 115-131 


\section{Economics Working Papers}

2015-02: Torben M. Andersen: The Nordic welfare model and welfare services - Can we maintain acceptable standards?

2015-03: Nina Neubecker, Marcel Smolka and Anne Steinbacher: Networks and Selection in International Migration to Spain

2015-04: Sylvanus Kwaku Afesorgbor and Kaleb Girma Abreha: Preferential Market Access, Foreign Aid and Economic Development

2015-05: Ritwik Banerjee: Corruption, Norm Violation and Decay in Social Capital

2015-06: Christian Giødesen Lund and Rune Vejlin: Documenting and Improving the Hourly Wage Measure in the Danish IDA Database

2015-07: $\quad$ Anne Brink Nandrup: Do class size effects differ across grades?

2015-08: Mugdha Vaidya, Meghna Katoch and Nabanita Datta Gupta: The Impact of Household Participation in Community Based Organizations on Child Health and Education in Rural India

2015-09: Paola A. Barrientos Q., Niels-Hugo Blunch and Nabanita Datta Gupta: Income Convergence and the Flow out of Poverty in India, 1994-2005

2015-10: Peter S. Eppinger, Nicole Meythaler, Marc-Manuel Sindlinger and Marcel Smolka: The Great Trade Collapse and the Spanish Export Miracle: Firm-level Evidence from the Crisis

2015-11: Ella Paldam and Martin Paldam: The political economy of churches in Denmark over 700 years

2015-12: Ina C. Jäkel and Marcel Smolka: Trade Policy Preferences and the Factor Content of Trade

2015-13: Rene Saran and Norovsambuu Tumennasan: Implementation by Sortition in Nonexclusive Information Economies:

2015-14: Torben M. Andersen: The Greenlandic Economy - Structure and Prospects

2015-15: Jos Jansen: A Note on Quality Disclosure and Competition 